\title{
Clinico-laboratory profile and mortality in plasmodium falciparum and vivax malaria in a tertiary centre
}

\author{
Chaudhary P. ${ }^{1}$, Piparsania S. ${ }^{2}$, Doharey NC $^{3}$ \\ ${ }^{1}$ Dr. Prashant Chaudhary, Assistant Professor, ${ }^{2}$ Dr. Saurabh Piparsania, Assistant Professor, ${ }^{3}$ Dr. Nagesh Chandra \\ Doharey, Senior Resident, all authors are affiliated with Department of Pediatrics, Index Medical College Hospital and \\ Research Centre, Indore (M.P.) India.
}

Corresponding Author: Dr. Saurabh Piparsania, Address- 62, Goyal Avenue, Near DPS and Ashirwaad Vila, Nipania. Indore, M.P. India. Email: sourabhpiparsania@gmail.com

\begin{abstract}
Introduction: Malaria is a disease of global health importance and currently, $95 \%$ of the Indian population lives in malaria endemic area. Malaria parasite profile has been changing significantly over the years and is responsible for significant mortality and morbidity. Objective: To study the clinic-hematological profile and mortality in plasmodium vivax and falciparum malaria. Methodology: Hospital based observational study in a tertiary care centre for a period of 4 years including children $<14$ years of age who were tested positive for plasmodium vivax/falciparum. Results: A total of 230 confirmed cases of malaria were taken up, of which 141 were P. falciparum $(61.30 \%)$ and 69 were P. vivax (30\%) positive. 20 patients were positive for both $\mathrm{Pf}$ and $\mathrm{Pv}(8.70 \%)$. Fever with chills and/or rigor was most common symptom and pallor followed by splenomegaly was the most common physical signs. The most common hematological abnormality noted was anemia followed by thrombocytopenia. Anemia was more common in p. falciparum and in children below 5 years of age. Mortality was highest in p. falciparum malaria (5.67\%) followed by mixed infection (5\%) and Pv (2.89\%). Cerebral malaria was most common cause of mortality (6 cases) followed by acute renal failure and shock. Complications were more common with Pf group, though they were also seen in Pv group. Conclusion: Cerebral malaria is the most lethal entity of severe malaria and children are more prone than other susceptible groups. Encephalopathy, shock and renal failure at the time of presentation were poor prognostic factors, while anemia and thrombocytopenia were not found to be associated with adverse outcome.
\end{abstract}

Keywords: Anemia, Falciparum Malaria, Fever with chills, Splenomegaly, Vivax Malaria

\section{Introduction}

Malaria is a disease of global health importance and afflicts more than ninety countries and territories in the tropical and subtropical regions. In the World malaria report 2017, the World Health Organization (WHO) estimates 196-263 million malaria cases in 2016 globally, with estimated 4,45,000 deaths of which approximately $6 \%$ of the deaths were reported from India [1]. Currently, 95\% of the population of India lives in malaria endemic area (National Vector Borne Disease Control Programme- NVBDCP) [2]. In 2016, approximately $6 \%$ of total malaria cases were reported from India, of which $51 \%$ were plasmodium vivax $(\mathrm{Pv})$. Orissa, Jharkhand, Madhya Pradesh, Chhattisgarh and West Bengal are contributing more than $60 \%$ of reported (confirmed) malaria cases in India [3]. Madhya

Manuscript received: $30^{\text {th }}$ March 2018

Reviewed: $7^{\text {th }}$ April 2018

Author Corrected: $14^{\text {th }}$ April 2018

Accepted for Publication: $19^{\text {th }}$ April 2018
Pradesh is situated in the central part of India. According to an estimate, 60.35 million population of Madhya Pradesh (MP), accounting for $6 \%$ of the total population of India (1,028 million), contributes to $8.6 \%$ of the total malaria cases [4]. Areas with more than $30 \%$ of plasmodium falciparum (Pf) cases are categorized as high risk. These include North East India, Orissa, Jharkhand, Madhya Pradesh, West Bengal, Maharashtra and Andhra Pradesh.

Malaria parasite profile has been changing significantly over the years. In the recent past, there has been a steady increase in percentage of Pf cases across the country. Clinical profile of complicated Pf has changed from cerebral malaria as the commonest presentation in to jaundice, profound thrombocytopenia, renal failure and multi-organ dysfunction ( 2 or more complications) as increasingly common complications. Traditionally, 
plasmodium falciparum (Pf) is considered responsible for severe malaria and malaria mortality in literature. However, there is growing evidence that plasmodium vivax $(\mathrm{Pv})$ is responsible for a significant burden of disease worldwide [5]. Severe and fatal vivax malaria is an emerging entity and challenges the perception of $\mathrm{Pv}$ as a benign tertian disease [6].

Therefore, our study was planned to look for clinical profile and lab parameters of plasmodium falciparum and plasmodium vivax malaria and contribution to morbidity and mortality in children in our hospital which is a tertiary care hospital in central India and caters to population from Indore as well as neighboring tribal district.

\section{Material and Methods}

Study design and period: It is a hospital based observational study from October 2013 to September 2017 in Index medical college hospital and research centre (IMCHRC), a tertiary care hospital catering population from Indore as well as neighboring districts, for a period of 4 years.

Detailed clinical, biochemical and hematological characteristics were recorded. There is no defined geographic area; hence, denominator population cannot be defined.
Inclusion Criteria: Children $<14$ years of age with fever admitted to IMCHRC who were tested positive for plasmodium vivax/falciparum during the period from October 2013 to September 2017 were taken up. Presence of malarial parasite on thick and thin peripheral smear and/or positive rapid malaria antigen test (rapid immuno-chromatogenic test) was considered as diagnostic for malaria. Rapid diagnostic test (RDT) was performed according to the manufacturer's instructions. Categorization into severe malaria and their treatment was as per WHO guidelines. Admission laboratory values were used for patient classification and data analysis.

Exclusion criteria: All patients were investigated for other co-existent infections including enteric fever, dengue and hepatitis, whenever deemed relevant. Patients having another infection with plasmodium such as enteric fever and hepatitis were excluded. Patients affected with chronic hemolytic anemia and chronic liver diseases were also excluded from the study.

Statistical Analysis: All the patients were evaluated as per proforma (for clinical features and laboratory parameters). The statistical calculation was done using SPSS version 17 software. The categorical data was analyzed by Chi square and Fisher's exact test whereas the quantitative data was analyzed using unpaired t test.

\section{Results}

A total of 230 confirmed cases of malaria were taken up from admitted patients in Index medical college, hospital and research centre, Indore, over 4 years from October 2013 to September 2017 of which 141 were p. falciparum and 69 were p. vivax positive. 20 patients were positive for both Pf and Pv. Distribution of cases occurred throughout the year with a peak incidence between September and November (57\% of total cases occurred in these 3 months). Out of 230 cases, p. falciparum was the most frequently observed species. It was seen in more than half the cases i.e. $61.3 \%$. p. vivax was seen in $30 \%$ of cases. Mixed infection consisting of both vivax and falciparum was observed in $8.7 \%$ cases. Fifty three percent of total cases occurred in $<5$-year age group. Proportion of Pv patients from younger age group ( $<5$ yr) was significantly higher $(65 \%)$.

Table-1: Age and sex distribution in plasmodium species.

\begin{tabular}{|c|c|c|c|c|c|c|}
\hline Age & \multicolumn{2}{|c|}{$<5$ Years } & \multicolumn{2}{|c|}{ 5-10 Years } & \multicolumn{2}{|c|}{$>10$ Years } \\
\hline Sex $\rightarrow$ & \multirow[t]{2}{*}{ Male } & \multirow[t]{2}{*}{ Female } & \multirow[t]{2}{*}{ Male } & \multirow[t]{2}{*}{ Female } & \multirow[t]{2}{*}{ Male } & \multirow[t]{2}{*}{ Female } \\
\hline species & & & & & & \\
\hline $\mathrm{Pf}$ & $\begin{array}{c}35 \\
(24.8 \%) \\
\end{array}$ & $\begin{array}{c}33 \\
(23.4 \%) \\
\end{array}$ & $\begin{array}{c}26 \\
(18.4 \%) \\
\end{array}$ & $\begin{array}{c}22 \\
(15.6 \%)\end{array}$ & $\begin{array}{c}15 \\
(10.6 \%)\end{array}$ & $\begin{array}{c}10 \\
(7 \%)\end{array}$ \\
\hline Total & \multicolumn{2}{|c|}{$48.2 \%$} & \multicolumn{2}{|c|}{$34 \%$} & \multicolumn{2}{|c|}{$17.6 \%$} \\
\hline $\mathrm{PV}$ & $\begin{array}{c}24 \\
(34.7 \%) \\
\end{array}$ & $\begin{array}{c}21 \\
(30.4 \%) \\
\end{array}$ & $\begin{array}{c}12 \\
(17.3 \%) \\
\end{array}$ & $\begin{array}{c}4 \\
(5.7 \%) \\
\end{array}$ & $\begin{array}{c}6 \\
(8.6 \%) \\
\end{array}$ & $\begin{array}{c}2 \\
(1.4 \%) \\
\end{array}$ \\
\hline Total & \multicolumn{2}{|c|}{$65.1 \%$} & \multicolumn{2}{|c|}{$23 \%$} & \multicolumn{2}{|c|}{$10 \%$} \\
\hline Mix & $\begin{array}{c}5 \\
(25 \%) \\
\end{array}$ & $\begin{array}{c}4 \\
(20 \%) \\
\end{array}$ & $\begin{array}{c}4 \\
(20 \%) \\
\end{array}$ & $\begin{array}{c}4 \\
(20 \%) \\
\end{array}$ & $\begin{array}{c}2 \\
(10 \%) \\
\end{array}$ & $\begin{array}{c}1 \\
(5 \%) \\
\end{array}$ \\
\hline Total & \multicolumn{2}{|c|}{$45 \%$} & \multicolumn{2}{|c|}{$40 \%$} & \multicolumn{2}{|c|}{$25 \%$} \\
\hline
\end{tabular}


The numbers of males affected in our study were slightly higher than females. The overall male to female (M:F) ratio was 1.28. In the $<5 \mathrm{yr}$ age group, $\mathrm{M}$ : F ratio was almost equal (1.1:1) but after this period of life males were affected predominantly [1.4:1 in 5-10 year age group and 1.77:1 in $>10$ year age group). M:F ratio was significantly higher in Pv group (1.55:1).

Table-2: Comparison of duration of stay in Plasmodium falciparum and Plasmodium vivax malaria.

\begin{tabular}{|c|c|c|c|c|c|c|c|}
\hline \multirow{2}{*}{} & \multicolumn{2}{|c|}{ P. falciparum } & \multicolumn{2}{|c|}{ P. vivax } & \multicolumn{2}{|c|}{ Mix } & \\
\cline { 2 - 8 } & Mean & SD & Mean & SD & Mean & SD & P value \\
\hline Duration of hospitalization & 5.26 & 2.41 & 4.88 & 1.97 & 5.55 & 2.46 & 0.405 \\
\hline
\end{tabular}

$\mathrm{P}$ value $<0.001$ highly significant; $<0.05$ significant; $>0.05$ not significant

Duration of stay: Mean duration of stay in hospital was 5.26 days and 4.88 days in Pf and Pv respectively while in mixed infection it was 5.55 days.

It was not significant statistically suggesting that both falciparum and vivax took nearly equal time to recover (table2).

Table-3: Clinical profile of Pf and Pv malaria.

\begin{tabular}{|c|c|c|c|}
\hline Clinical features & $\begin{array}{c}\text { Plasmodium } \\
\text { falciparum }\end{array}$ & Plasmodium vivax & Mix infection \\
\hline Fever & $141(100 \%)$ & $69(100 \%)$ & $20(100 \%)$ \\
\hline Chills and Rigors & $83(58.8 \%)$ & $35(50.7 \%)$ & $11(55 \%)$ \\
\hline Vomiting & $49(34.7 \%)$ & $26(37.7 \%)$ & $8(40 \%)$ \\
\hline Abdominal Pain & $36(25.5 \%)$ & $20(28.9 \%)$ & $2(10 \%)$ \\
\hline Diarrhea & $18(12.7 \%)$ & $6(8.6 \%)$ & $3(15 \%)$ \\
\hline Headache & $19(13.4 \%)$ & $13(18.8 \%)$ & $2(10 \%)$ \\
\hline Myalgia & $14(9.9 \%)$ & $11(15.9 \%)$ & $1(5 \%)$ \\
\hline Cough & $18(12.7 \%)$ & $12(17.3 \%)$ & $1(5 \%)$ \\
\hline Loss of consciousness & $29(20.5 \%)$ & $1(1.4 \%)$ & $15(75 \%)$ \\
\hline Convulsion & $17(12 \%)$ & $1(1.4 \%)$ & $3(15 \%)$ \\
\hline Splenomegaly & $70(49.6 \%)$ & $35(50.7 \%)$ & $2(10 \%)$ \\
\hline Icterus & $24(17.1 \%)$ & $10(14.4 \%)$ & $60 \%)$ \\
\hline Edema & $16(11.3 \%)$ & $9(13 \%)$ & $36(52.1 \%)$ \\
\hline
\end{tabular}

In our study chills and/or rigors was most common associated symptom with fever. Chills and/or rigor were most common symptom associated with both vivax and falciparum cases.

Nausea and vomiting, pain in abdomen, headache and diarrhea were the next complaints in decreasing order. Cough was a presenting complaint in $12.7 \%$ to $17.3 \%$ of the patients with falciparum and vivax respectively.

Pallor was the most frequent physical sign in our study; severe pallor was predominantly seen in falciparum cases. Splenomegaly was second most common sign followed by icterus with nearly equal distribution in vivax and falciparum cases. 
Table- 4: Hematological profile.

\begin{tabular}{|c|c|c|c|}
\hline Hb gm/dl & P. falciparum & P. vivax & P value \\
\hline$<5$ & $57(40.4 \%)$ & $10(14.4 \%)$ & $<0.001$ \\
\hline $5-7$ & $36(25.5 \%)$ & $20(28.9 \%)$ & 0.512 \\
\hline $7-10$ & $33(23.4 \%)$ & $26(18.4 \%)$ & 0.390 \\
\hline Platelets & $8(5.6 \%)$ & $4(5.7 \%)$ & 0.776 \\
\hline$<20,000$ & $64(45.3 \%)$ & $23(33.3 \%)$ & 0.090 \\
\hline $20,000-1$ lac & \multicolumn{3}{|l}{} \\
\hline WBC & $27(19.1 \%)$ & $15(21.7 \%)$ & 0.586 \\
\hline$<5,000$ & $21(14.8 \%)$ & $10(14.4 \%)$ & 0.884 \\
\hline
\end{tabular}

$\mathrm{P}$ value $<0.001$ highly significant $;<0.05$ significant; $>0.05$ not significant

Among hematological parameters, severe anemia $(\mathrm{Hb}<5 \mathrm{~g} / \mathrm{dl})$ was significantly more common in Pf group. Thrombocytopenia was more common in falciparum group but this difference was not significant statistically. Leucopenia and leukocytosis were observed equally in both groups.

Table-5: Complications observed in patients.

\begin{tabular}{|c|c|c|c|c|}
\hline Complications & Pf & $\mathbf{P v}$ & $\mathbf{P f}+\mathbf{P v}$ & P value \\
\hline $\begin{array}{c}\text { Severe anemia } \\
(\text { Hemoglobin }<5 \mathrm{~g} / \mathrm{dl})\end{array}$ & $\begin{array}{c}57 \\
(40.4 \%)\end{array}$ & $\begin{array}{c}10 \\
(14.4 \%)\end{array}$ & $\begin{array}{c}5 \\
(25 \%)\end{array}$ & $<0.001$ \\
\hline $\begin{array}{c}\text { Jaundice } \\
\text { (Serum bilirubin }>3 \mathrm{mg} / \mathrm{dl} \text { ) }\end{array}$ & $\begin{array}{c}13 \\
(9.2 \%)\end{array}$ & $\begin{array}{c}8 \\
(11.5 \%)\end{array}$ & $\begin{array}{c}2 \\
(10 \%)\end{array}$ & 0.474 \\
\hline $\begin{array}{l}\text { Thrombocytopenia } \\
\text { (platelets }<1 \text { lac) }\end{array}$ & $\begin{array}{c}72 \\
(51 \%)\end{array}$ & $\begin{array}{c}27 \\
(39.1 \%)\end{array}$ & $\begin{array}{c}11 \\
(55 \%)\end{array}$ & 0.082 \\
\hline Cerebral malaria & $\begin{array}{c}29 \\
(20.5 \%)\end{array}$ & $\begin{array}{c}1 \\
(1.4 \%)\end{array}$ & $\begin{array}{c}1 \\
(5 \%)\end{array}$ & $<0.001$ \\
\hline $\begin{array}{c}\text { Renal failure } \\
\text { (Serum creatinine }>3 \mathrm{mg} / \mathrm{dl} \text { ) }\end{array}$ & $\begin{array}{c}3 \\
(2.1 \%)\end{array}$ & $\begin{array}{c}1 \\
(1.4 \%)\end{array}$ & - & 0.876 \\
\hline $\begin{array}{c}\text { Hypoglycemia } \\
(\text { Blood glucose. }<40 \mathrm{mg} / \mathrm{dl})\end{array}$ & $\begin{array}{c}4 \\
(2.8 \%)\end{array}$ & - & - & - \\
\hline Algid Malaria & $\begin{array}{c}3 \\
(2.1 \%)\end{array}$ & - & - & - \\
\hline
\end{tabular}

In our study cerebral malaria, severe anemia, shock and hypoglycemia were significantly more frequently observed in Pf group, while profound thrombocytopenia, hepatic and renal complications were equally seen in both groups. Mixed infection showed a complication rate in between Pf and Pv.

Table-6: Mortality Pattern of Malaria.

\begin{tabular}{|c|c|c|}
\hline $\mathrm{Pf}=8(5.67 \%)$ & $\mathrm{Pv}=2(2.89 \%)$ & $\mathrm{Pf}+\mathrm{Pv}=1(5 \%)$ \\
\hline Cerebral malaria $=5$ & Jaundice $=1$ & Cerebral malaria $=1$ \\
\hline $\mathrm{ARF}=1$ & $\mathrm{ARF}=1$ & \\
\hline Shock $=1$ & & \\
\hline $\mathrm{MODS}=1$ & & \\
\hline
\end{tabular}

In our study mortality rate in malaria was 4.7\% (11/230). Mortality was highest in Pf (5.67\%) followed by mixed infection (5\%) and $\mathrm{Pv}(2.89 \%)$ group. Cerebral malaria was most common cause of mortality (6 cases) followed by acute renal failure (ARF) and shock. One patient had 2 or more clinical syndromes simultaneously and was classified as multiorgan dysfunction syndrome (MODS). 


\section{Discussion}

Among cases with malaria, proportion of $\mathrm{Pv}$ and $\mathrm{Pf}$ varies in different parts of India, with $10-30 \%$ cases caused by $\mathrm{Pf}$ and remaining $70-90 \%$ by $\mathrm{Pv}$ in most parts of the country. Kumar et al [7] in their analysis on 'burden of malaria in India: retrospective and prospective view' have stated a continued rise in Pf and its proportion has gradually risen to nearly $50 \%$ of total cases in recent years. Hazra et al [8] from Calcutta has reported $73.3 \% \mathrm{Pv}$ and $26.7 \% \mathrm{Pf}$ in their study of 225 cases. Patel et al from Orissa [9] has reported 54.5\% Pv, $36.6 \% \mathrm{Pf}$ and $8.9 \%$ of mixed infection. This shows that the parasitic profile is different in various places. In present series, percentage of falciparum cases $(61.3 \%)$ was high. This is a part of overall trend of increasing number of falciparum cases.

Yadav et al [10] from New Delhi has reported higher proportion of vivax malaria $(74.8 \%)$ in children $<5$ year of age compared with Pf (55.7). Kochar et al [11] has also reported higher proportion of vivax malaria in children $<5$ year of age $(67.4 \%)$ compared with $\mathrm{Pf}$ (30.4\%). In our study also, Pv malaria was more frequently observed in younger children $(<5$ year age) in comparison to Pf malaria, which affected children of all ages. Proportion of $\mathrm{Pv}$ patients from younger age group ( $<5$ year) was significantly higher $(65 \%)$ in our study.

Bhakshi et al in his study on adult malaria cases have shown an M: F ratio of 2.9: 1. Many other studies have shown higher male to female ratio, ranging from 1.5: 1 to $3: 1$. The incidence of malaria is more in adult men than in women due to the working pattern and sleeping outside the house in rural areas i.e. men are exposed to mosquito bites outdoors whereas females are less exposed. In present series, male to female ratio in the younger $(<5$ year) age group was almost equal but after this period of life male children were affected predominantly. This is in line with the adolescent and adult malaria trend.

Severe anemia was significantly more frequently observed in Pf [40.4\%] group than Pv [14.4\%] group in our study. Parakh et al [12] in their work concluded that patients with Pv infection are less likely to present with severe anemia, as they have lower parasite densities than Pf patients, and therefore, the likelihood of having profound anemia is less, even if other immunological factors may contribute to red cell destruction. Kochar et al [11] and Yadav et al [10] have reported that severe anemia is significantly more frequently observed in falciparum patients than vivax patients. Price et al [13] studied in 2001 found out that $18.1 \%$ patients of malaria presented with severe anemia (hematocrit $<30 \%$ ) and $1 \%$ of patients required blood transfusion. Sharma et al [14] in their study of 30 cases of adult falciparum malaria observed severe anemia in $10 \%$ of cases. Perrin et al [15] in their study concluded that in tropical areas anemia tend to be more severe in children whereas only moderate anemia was noted in adolescents and adults.

Overall thrombocytopenia was more common in falciparum group $[45.3 \% \mathrm{Vs} 33.3 \%]$ but profound thrombocytopenia was seen in both falciparum and vivax [5.6\% and 5.7\%] respectively. This is in line with the conclusion of Jadhav et al [16] that presence of thrombocytopenia is not a distinguishing feature between vivax and falciparum malaria. Profound thrombocytopenia is a well-recognized complication of Pf malaria but has been less well described in $\mathrm{PV}$ malaria.

A recent study from Venezuela by Rodriguez- Morales et al [17] reported thrombocytopenia in 58.9\% cases with Pv malaria. Another series on adult patients with Pv mono-infection by Kochar [18] reported severe thrombocytopenia in $12.5 \%$ cases. Krishnan et al [19] in 2003 reported thrombocytopenia in $40 \%$ patients diagnosed with malaria. Sharma et al [14] in their study of 30 cases of falciparum malaria concluded that $90 \%$ of the cases had thrombocytopenia. The high prevalence of thrombocytopenia observed in malaria patients establishes thrombocytopenia as a key indicator of malaria in febrile patients. Erhart et al [20] in 2004 concluded in their study that patients with platelet count less than 1.5 lakh were 12-15 times more likely to had malaria.

Yadav et al [10] from New Delhi in 2011 reported hepatitis in $17.6 \%$ and $16.5 \%$ of falciparum and vivax cases respectively in pediatric patients. Jaundice was present in $19 \%$ adult falciparum cases in study of Mishra [21] in 2008. Hazra et al [8] from Kolkata reported jaundice in $9.09 \%$ of p. vivax cases. In our study significant hepatic involvement causing serum total bilirubin to rise to more than $3 \mathrm{mg} / \mathrm{dl}$ was present in $9.2 \%$ of falciparum cases and $11.5 \%$ of vivax cases. Mix infection cases developed this complication in $10 \%$. Thus jaundice was seen equally in falciparum and vivax group. Other studies done on both pediatric and adult population have revealed the same result. In our study we found out that $62.5 \%$ of total vivax hepatitis 
affected younger children of $<5$ year age group but only $23 \%$ of total falciparum hepatitis occurred in this age group. Similarly Kocher et al [11] from Bikaner, Rajasthan in 2010 concluded that younger children in 0-5 year age group had more predilections for severe p.vivax hepatitis whereas older children in 5-10 year age group and young adolescents were more predilicted to $\mathrm{p}$. falciparum hepatitis.

A significant percentage of patients having malaria with jaundice fulfill the criteria for malarial hepatopathy. It should be considered in patients presenting with acute febrile illness with jaundice so that specific treatment can be given. Jaundice was predominantly the conjugated type. On clinical examination it had most common association with splenomegaly (75\%) in $\mathrm{Pv}$ and severe anemia [62\%] in Pf group.

Cerebral malaria is the most lethal entity of severe malaria and children are more prone than other susceptible groups [22]. Kochar et al [11] has reported $10.9 \%$ incidence of cerebral malaria in Pf cases in 2001. Kochar reported generalized convulsions in 21.31\% cases of cerebral malaria from Rajasthan. Yadav et al [10] reported cerebral malaria in $16.8 \%$ of falciparum cases.

Mishra et al [21] in 2008 found cerebral malaria in 11\% of total falciparum cases. Nand et al [23] in 2001 reported that $17 \%$ cases with plasmodium falciparum presented as cerebral malaria. In our study 29 falciparum patients $(20.5 \%)$ had cerebral malaria. Seventeen patients [58.6\%] had convulsions along with loss of consciousness. Only one case of cerebral malaria attributable to vivax was seen. Thus cerebral malaria is a complication which is most strongly associated with falciparum malaria.

Percentage of severe malaria attributable to vivax was $20.6 \%$ in our study. Severe malaria is classically associated with Pf infection but sporadically, all complications associated with Pf malaria have also been reported in Pv malaria. Price et al [24] in his recent study, has shown that $21-27 \%$ of patients with severe malaria have $\mathrm{Pv}$ mono-infection and clinical spectrum of these cases is broad with an overall mortality of 0.8 $1.6 \%$. Similar high proportion of severe Pv malaria has been reported in studies in children by Kochar et al [11] and Yadav et al [10]. Our results are consistent with them.

Mix infections behaved like falciparum in respect to clinical features and complications in our study. Earlier studies of Luxemburger et al [25] and Maitland et al [26] in Thailand in last decade suggested a protective effect of $\mathrm{Pv}$ and suggested that $\mathrm{Pv}$ co-infection with Pf may attenuate severity of Pf malaria. However, recent studies from Tjitra et al [27] from Papua New Guinea have reported that mixed infections have features comparable to falciparum.

There was no significant difference in symptomatology of vivax and falciparum except the presence of loss of consciousness and seizure which were seen with falciparum patients (with the exception of one case of vivax). Chills and rigor was most common symptom associated with both vivax and falciparum cases. Nausea and vomiting, pain in abdomen, headache, diarrhea and cough were the next complaints in decreasing order. Vomiting was observed in $43.3 \%$ of the patients in the study conducted by Mehta et al and it was seen in $34.7 \%$ of the patients of our study.

Pallor was most common physical sign which was predominantly seen in falciparum cases. Splenomegaly was 2 nd common sign followed by icterus. Both had nearly equal distribution in vivax and falciparum cases. Splenomegaly was present in $49.6 \%$ and $50.7 \%$ of Pf and $\mathrm{Pv}$ cases respectively. Hazra et al had reported splenomegaly in $18.18 \%$ of $\mathrm{Pv}$ and $40 \%$ of $\mathrm{Pf}$ cases. Malhotra et al reported splenomegaly in $31.25 \%$ and Murthy et al in $50 \%$ of malaria cases.

Encephalopathy, shock, MODS and renal failure at the time of presentation were poor prognostic factors, while anemia and thrombocytopenia were not found to be associated with adverse outcome. Nature of thrombocytopenia in malaria is benign, mostly recovering with antimalarials without platelet transfusions. In our study, mortality rate of malaria was found to be $4.7 \%$. Pf was associated with higher mortality rate as compared to $\mathrm{Pv}$. Complications were more common with Pf group, though they were also seen in $\mathrm{Pv}$ group.

\section{Conclusion}

In this observational study, conducted on hospitalized children diagnosed with malaria, a total of $141(61.3 \%)$ patients with plasmodium falciparum (Pf), 69 (30\%) with plasmodium vivax (Pv) and $20(8.7 \%)$ with mixed infections were taken up. Distribution of cases occurred throughout the year with a peak incidence between September and November. Percentage of falciparum cases was high. This is a part of overall trend of increasing number of falciparum cases. Proportion of $\mathrm{Pv}$ patients from younger age group $(<5 \mathrm{yr})$ was 
significantly higher $(65 \%)$. In the $<5 \mathrm{yr}$ age group, M: $\mathrm{F}$ ratio was almost equal but after this period of life male children were affected predominantly. Cerebral malaria, severe anemia, shock and hypo-glycemia were more frequently observed in Pf group while difference in presence of thrombocytopenia and hepatitis were not statistically significant between the two groups. There was no significant difference in symptomatology of vivax and falciparum, except the presence of loss of consciousness and seizures in later. Mix infections behaved like falciparum in respect to clinical features and complications in our study. Percentage of severe malaria attributable to vivax was $20.6 \%$ in our study.

Cerebral malaria is the most lethal entity of severe malaria and children are more prone than other susceptible groups. Encephalopathy, shock and renal failure at the time of presentation were poor prognostic factors, while anemia and thrombocytopenia were not found to be associated with adverse outcome.

Thrombocytopenia is a key indicator of malaria in febrile patients. Nature of thrombocytopenia in malaria is benign, mostly recovering with antimalarials without platelet transfusions. In our study, mortality rate of malaria was found to be $4.7 \%$. Pf was associated with higher mortality rate as compared to Pv. Complications were more common with Pf group, though they were also seen in Pv group.

What this study adds- The incidence of complicated plasmodium falciparum malaria cases is on the rise; encephalopathy, shock and renal failure at the time of presentation are poor prognostic factors. Thrombocytopenia is a key indicator of malaria in febrile patients.

Author's Contribution: PC, SP and ND: conception and design of the study and interpretation of data. PC: collected and analysed the data. SP: drafting of manuscript, critical revision of the manuscript for important intellectual content. The final version of the manuscript was approved by all authors.

References: 27

Funding: Nil, Conflict of interest: None initiated, Perission from IRB: Yes

\section{References}

1.World malaria report2017.World HealthOrganization. Geneva. [Cited 2018 Feb 10]. Available from: http:// apps. who.int/iris/ bitstream/handle /10665/ 259492/ 9789241565523-eng.pdf?sequence $=1$
2. National Vector Borne Disease Control Programme (NVBDCP). [Internet]. [Updated 2013 May30; cited 2018 Feb10]. Available from: http://www.health.mp. gov.in/ malaria.htm

3. Singh N, Dash AP, Thimasarn K. Fighting malaria in Madhya Pradesh (Central India): are we losing the battle? Malar J. 2009 May 7;8:93. doi: 10.1186/14752875-8-93.

4. Singh N, Dash AP, Varun BM, Kataria OM. Tribal Malaria. ICMR Bulletin. 2004; 34:1-10.

5.Yadav D, Chandra J, Dutta AK. Benign tertian malaria: how benign is it today? Indian J Pediatr. 2012 Apr; 79 (4): 525-7. doi: 10.1007/s12098-011-0514-x. Epub 2011 Jun 25.

6. Genton B, D'Acremont V, Rare L, BaeaK, Reeder JC, AlpersMP, et al. Plasmodium vivax and mixed infections are associated with severe malaria in children: a prospective cohort study from Papua New Guinea. PLos Med. 2008 Jun 17; 5 (6): e127. doi:10.1371/journal.pmed.0050127. [ PubMed].

7. Kumar A, Valecha N, Jain T, Dash AP. Burden of malaria in India: retrospective and prospective view. Am J Trop Med Hyg. 2007 Dec;77 (6 suppl):69-78. doi: 10.4269/ajtmh.2007.77.69

8. Hazra BR, Chowdhury RS, Saha SK, Ghosh $\mathrm{MB}$, Mazumder AK. Changing scenario of malaria: a study at Calcutta. Indian J Malariol. 1998 Jun; 35(2):111-6. [PubMed]

9. Patel DN, Pradeep P, Surti MM, Agarwal SB. Clinical manifestations of complicated Malaria- an overview. JIACM. 2003; 4(4):323-31.

10.Yadav D, Chandra J, Aneja S, Kumar V, Kumar P, Dutta AK. Changing profile of severe malaria in north Indian children. Indian J Pediatr. 2012 Apr;79(4):483-7. doi: 10.1007/s12098-011-0603-x. Epub 2011 Nov 18.

11. Kochar DK, Tanwar GS, Khatri PC, Kochar SK, Sengar GS, Gupta A et al. Clinical features of children hospitalized with malaria- a study from Bikaner, northwest India. Am J Trop Med Hyg. 2010;83:981-9. doi: 10.4269/ajtmh.2010.09-0633.[ PMC free article] [PubMed]

12. Parakh A, Agarwal N, Aggarwal A, Aneja A. Plasmodium vivax malaria in children : uncommon 
manifestations. Ann Trop Pediatr. 2009; 29 (4):2536.doi:10.1179/027249309X12547917868844.[PubMed]

13. Price RN, Simpson JA, Nosten F, Luxemburger C, Hkirjaroen L, ter Kuile F, Chongsuphajaisiddhi T, White NJ. Factors contributing to anemia after uncomplicated falciparum malaria. Am J Trop Med Hyg. 2001 Nov;65(5):614-22.

14. Sharma SK, Das RK, Das BK, Das PK. Haematological and coagulation profile in acute falciparum malaria. J Assoc Physicians India. 1992 Sep; 40 (9):581-3.

15. Perrin LH, Mackey LJ, Miescher PA. The hematology of malaria in man. Semin Hematol. 1982 Apr; 19(2): 70-82.

16. Jadhav UM, Patkar VS, Kadam NN. Thrombocytopenia in malaria--correlation with type and severity of malaria.J Assoc Physicians India.2004 Aug;52:615-8

17. Rodriguez-Morales AJ, Sanchez E, Vargas M, Piccolo C, Colina R, Arria M. Anemia and thrombocytopenia in children with plasmodium vivax malaria. $\mathrm{J}$ Trop Pediatr. 2006 Feb;52 (1):49-51. doi: 10.1093 /tropej/fmi069.

18. Kochar DK, Das A, Kochar SK, Saxena V, Sirohi P, Garg S, Kochar A, Khatri MP, Gupta V. Severe Plasmodium vivax malaria: a report on serial cases from Bikaner in northwestern India. Am J Trop Med Hyg. 2009 Feb;80(2):194-8.

19. Krishnan A, Karnad DR. Severe falciparum malaria: an important cause of multiple organ failure in Indian intensive care unit patients. Crit Care Med. 2003 Sep; 31(9):2278-84.

20. Erhart LM, Yingyuen K, Chuanak N, Buathong N, Laoboonchai A, Miller RS, Meshnick SR, Gasser RA
Jr, Wongsrichanalai C. Hematologic and clinical indices of malaria in a semi-immune population of western Thailand. Am J Trop Med Hyg. 2004 Jan;70(1):8-14.

21. Mishra SK, Mahanta KC, Mohanty S. Malaria associated acute renal failure--experience from Rourkela, eastern India. J Indian Med Assoc. 2008 Oct; 106 (10):640-2, 654.

22. Severe falciparum malaria. World Health Organization, Communicable Diseases Cluster. Trans R Soc Trop Med Hyg. 2000 Apr;94 Suppl 1:S1-90.

23. Nand N, Aggrawal H, Sharma M, Singh M. Systemic manifestations of malaria. Journal,Indian academy of clinical medicine.2001Jul-Sept;2(3):189-94.

24. Price RN, Douglas NM, Anstey NM. New developments in Plasmodium vivax malaria: severe disease and the rise of chloroquine resistance. Curr Opin Infect Dis. 2009 Oct;22(5):430-5. doi: 10.1097/QCO.0b013e32832f14c1.

25. Luxemburger C, Ricci F, Nosten F, Raimond D, Bathet S, White NJ. The epidemiology of severe malaria in an area of low transmission in Thailand. Trans R Soc Trop Med Hyg.1997May-Jun;91(3):256-62

26. Maitland K, Williams TN, Newbold CI. Plasmodium vevax and P.falciparum: Biological interactions and the possibility of cross-species immunity. Parasitol Today. 1997 Jun; 13 (6): 227-31. [PubMed]

27. Tjitra E, Anstey NM, Sugiarto P, Warikar N, Kenangalem E, Karyana M, Lampah DA, Price RN. Multidrug-resistant Plasmodium vivax associated with severe and fatal malaria: a prospective study in Papua, Indonesia. PLoS Med. 2008 Jun 17;5(6):e128. doi: 10. $1371 /$ journal.pmed.0050128.

\section{How to cite this article?}

Chaudhary P, Piparsania S, Doharey NC. Clinico-laboratory profile and mortality in plasmodium falciparum and vivax malaria in a tertiary centre. Int J Pediatr Res. 2018;5(4):188-195. doi:10.17511/ijpr.2018.i04.06. 